\title{
Extended Frontobasal Approach for Skull Base Lesions
}

\author{
Mohd Faheem¹, Raj Kumar $^{2}$ Hanuman Prasad Prajapati ${ }^{1, \odot}$
}

${ }^{1}$ Department of Neurosurgery, Uttar Pradesh University of Medical

Address for correspondence Raj Kumar, MBBS, MS, MCh, PhD, Sciences, Saifai, Etawah, Uttar Pradesh, India

${ }^{2}$ Department of Neurosurgery, Uttar Pradesh University of Medical Sciences, Saifai, Etawah, Uttar Pradesh, India

FRCS, MRCS, FACET, FAMS, FNS, DSc, Vice chancellor,

Uttar Pradesh University of Medical Sciences, Saifai, Etawah 206130, Uttar Pradesh, India (e-mail: rajkumar1959@gmail.com).

Indian J Neurosurg 2021;1:49-53.

\begin{abstract}
Keywords

- extended frontobasal approach

- skull base

- paranasal sinuses

Background Lesions involving the skull base can be approached by a variety of surgical corridors and extended frontobasal approach is one of them. It provides quite a wide exposure to lesions in the midline of anterior skull base, paranasal sinuses, and sphenoclival region.

Objective To share our experience, and list the merits and demerits, of this approach for anterior skull base lesions.

Methods A total of six cases were operated using extended frontobasal approach. Four of them were skull base tumors with extensive involvement of paranansal sinuses and extension into sellar, parasellar, and clival region. Fronto-orbital and sphenoethmoidal osteotomy provided adequate surgical access, thereby facilitating their excision. Two cases of frontonaso-orbital encephalocele with large bone defect at anterior skull base were also operated upon. Skull base repair was performed using autologous bone graft, pericranium, and fibrin glue.

Results Gross total excision was achieved in four cases of skull base tumors with good cosmesis as transfacial access was obviated. Excision, repair, and reconstruction of two patients with frontonaso-orbital encephalocele were also done with acceptable cosmesis. Conclusion The extended frontobasal approach is an excellent alternative for extensive anterior skull base tumors (up to posterior skull base), and also for the repair of large malformative lesions of the anterior skull base.
\end{abstract}

\section{Introduction}

The extended frontobasal approach provides an adequate exposure to lesions of the skull base (anterior, middle, and part of posterior), paranasal sinuses, and sphenoclival region. This approach was originally described by Shekhar et $\mathrm{al}^{1}$ and is considered a modification of the transbasal approach. ${ }^{2}$ Depending upon the tumor's location, it combines bifrontal craniotomy with an orbitonasal-ethmoidal osteotomy as well as sphenoethmoidotomy to gain access to the skull base. ${ }^{3}$ Reconstruction of the skull base is the most important step in this technique to avoid cerebrospinal (CSF) leak, brain herniation, meningitis, and wound infection.

In the present series, extended frontobasal approach was used to deal with lesions (congenital, craniofacial, and acquired) of the anterior skull base with extension into paranasal sinuses and sphenoclival region.

DOI https://doi.org/

$10.1055 / \mathrm{s}-0040-1716931$

ISSN 2277-954X.

\section{Materials and Methods}

Four cases with extensive skull base tumors (anterior, middle, and posterior) along with extension into adjacent structures, and two patients of congenital frontonaso-orbital encephalocele having large skull base defects were operated upon with the extended frontobasal approach ( - Table $\mathbf{1}$ ).

\section{Clinical and Radiological Profile}

All the patients were evaluated by a battery of radiological investigations, including contrast-enhanced MRI, CT scan with bony reconstruction, and $\mathrm{CT}$ angiography to look for the possible involvement of carotid artery and feeder vessels by the skull base tumor. The decision regarding the operative procedure was made by defining the extent and degree of involvement of adjacent structures.

(c) 2021. Neurological Surgeons' Society of India.

This is an open access article published by Thieme under the terms of the Creative Commons Attribution-NonDerivative-NonCommercial-License, permitting copying and reproduction so long as the original work is given appropriate credit. Contents may not be used for commercial purposes, or adapted, remixed, transformed or built upon. (https://creativecommons.org/licenses/by-nc-nd/4.0/).

Thieme Medical and Scientific Publishers Pvt. Ltd. A-12, 2nd Floor, Sector 2, Noida-201301 UP, India 
Table 1 Clinical detail and follow up of all the patients

\begin{tabular}{|c|c|c|c|c|c|c|}
\hline S. no & Age/sex & Clinical status & Radiology & Surgery & $\begin{array}{l}\text { Histopatological } \\
\text { examination }\end{array}$ & Follow-up \\
\hline 1. & $14 \mathrm{y} / \mathrm{male}$ & $\begin{array}{l}\text { Diminution of vision-8 } \\
\text { months, headache-6 } \\
\text { months, only percep- } \\
\text { tion of light present in } \\
\text { bilateral eye, and mild } \\
\text { papilledema on fundus } \\
\text { examination. }\end{array}$ & $\begin{array}{l}\text { Contrast-enhanced mass in } \\
\text { ethmoid sinuses, sphenoid } \\
\text { sinus, sellar, parasellar } \\
\text { region, and sphenoclival } \\
\text { region. }\end{array}$ & $\begin{array}{l}\text { Frontobasal } \\
\text { approach with } \\
\text { sphenoethmoidotomy. }\end{array}$ & $\begin{array}{l}\text { Nasopharyngeal } \\
\text { angiofibroma }\end{array}$ & $\begin{array}{l}\text { Vision improved } \\
\text { to 6/36 and 6/24 in } \\
\text { right and left eye, } \\
\text { respectively, and } \\
\text { headache subsided }\end{array}$ \\
\hline 2. & $19 \mathrm{y} / \mathrm{male}$ & $\begin{array}{l}\text { Diminution of vision-6 } \\
\text { months, headache-4 } \\
\text { months, epistaxis-two } \\
\text { episodes, nasal } \\
\text { obstruction-4 } \\
\text { months. } \\
\text { Visual acuity-6/9 } \\
\text { right, 6/36 left. }\end{array}$ & $\begin{array}{l}\text { Contrast-enhanced mass } \\
\text { in frontal sinus, ethmoid, } \\
\text { sphenoid sinus, and sphe- } \\
\text { noclival region with bony } \\
\text { destruction in clival area. } \\
\text { Extension into basifrontal } \\
\text { area was present bilaterally. }\end{array}$ & $\begin{array}{l}\text { Frontobasal } \\
\text { approach with } \\
\text { sphenoethmoidotomy. }\end{array}$ & $\begin{array}{l}\text { Nasopharyngeal } \\
\text { angiofibroma }\end{array}$ & $\begin{array}{l}\text { Vision improved } \\
\text { and headache } \\
\text { subsided. } \\
\text { Epistaxis subsided }\end{array}$ \\
\hline 3. & $50 \mathrm{y} /$ Male & $\begin{array}{l}\text { Diminution of } \\
\text { vision-12 months, } \\
\text { headache-3.5months, } \\
\text { diplopia-3 months } \\
\text { Visual acuity-6/9 } \\
\text { bilaterally, mild } \\
\text { papilledema. }\end{array}$ & $\begin{array}{l}\text { Large contrast-enhanced } \\
\text { mass in clival area with } \\
\text { extension into sphenoid } \\
\text { sinus and ethmoid sinus. }\end{array}$ & $\begin{array}{l}\text { Frontobasal } \\
\text { approach with } \\
\text { sphenoethmoidotomy. }\end{array}$ & Clival chordoma & $\begin{array}{l}\text { Radiotherapy and } \\
\text { chemotherapy } \\
\text { given. } \\
\text { No recurrence at } \\
1 \text { year of follow-up. }\end{array}$ \\
\hline 4. & $52 \mathrm{y} /$ Male & $\begin{array}{l}\text { Nasal obstruction-12 } \\
\text { months, headache-4 } \\
\text { months, fever-2 } \\
\text { months. } \\
\text { On examination,-mass } \\
\text { was seen protruding } \\
\text { from the nose. }\end{array}$ & $\begin{array}{l}\text { Contrast-enhanced lesion } \\
\text { in paranasal sinus, protrud- } \\
\text { ing into cribriform plate }\end{array}$ & $\begin{array}{l}\text { Frontobasal } \\
\text { approach with } \\
\text { sphenoethmoidotomy. }\end{array}$ & Fungal granuloma & $\begin{array}{l}\text { Amphotericin B } \\
\text { started }\end{array}$ \\
\hline 5. & $\begin{array}{l}10 \mathrm{y} / \\
\text { Female }\end{array}$ & $\begin{array}{l}\text { Swelling at the } \\
\text { naso-orbital region } \\
\text { since birth. }\end{array}$ & $\begin{array}{l}\text { Sac entering into the fron- } \\
\text { to-orbital region from the } \\
\text { defect in frontal bone. } \\
\text { Bony defect in anterior } \\
\text { skull base and right medial } \\
\text { orbital wall. }\end{array}$ & $\begin{array}{l}\text { Frontobasal approach } \\
\text { with naso-orbital } \\
\text { osteotomy. }\end{array}$ & & $\begin{array}{l}\text { Revision surgery } \\
\text { advised for nose } \\
\text { reconstruction }\end{array}$ \\
\hline 6. & $\begin{array}{l}8 \mathrm{y} / \\
\text { Female }\end{array}$ & $\begin{array}{l}\text { Swelling at the } \\
\text { naso-orbital } \\
\text { region-since birth } \\
\text { Diplopia-2 months }\end{array}$ & $\begin{array}{l}\text { Sac entering into the fron- } \\
\text { to-orbital region from the } \\
\text { defect in frontal bone }\end{array}$ & $\begin{array}{l}\text { Frontobasal approach } \\
\text { with naso-orbital } \\
\text { osteotomy. }\end{array}$ & & \\
\hline
\end{tabular}
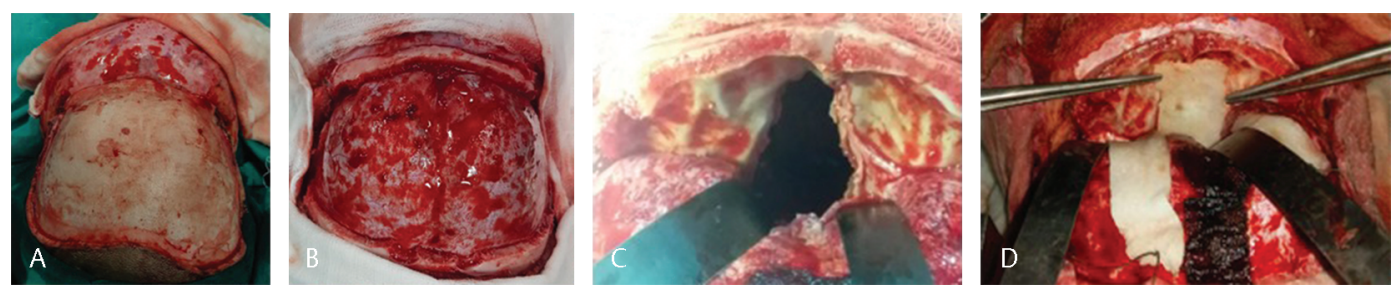

Fig. 1 (A) Preoperative picture showing bicoronal skin flap. (B) Bifrontal craniotomy. (C) Defect created at anterior skull base after tumor excision. (D) Reconstruction of skull base using bone graft.

Cases having extension into sellar region, parasellar region, and frontal region were tested for visual field and fundus. Pituitary hormone evaluation, neuropsychiatric evaluation, and neurotologic evaluation were also performed in cases of skull base tumors involving sellar and clival region.

\section{Operative Procedure}

Following endotracheal intubation, the patient's heads were secured in a supine and slightly extended position by Sugita's head frame. All cases received standard antibiotic prophylaxis. Cerebral dehydrants (mannitol and corticosteroids) were administered to relax the brain wherever needed.

\section{a. Incision and flap elevation}

A bicoronal skin incision was done half a centimeter anterior to the tragus to the opposite tragus. It avoids injury to the superficial temporal artery and branches of the facial nerve. The flap was raised in the subperiosteal plane and pericranium was preserved for the reconstruction of skull base (-Fig. 1A). 

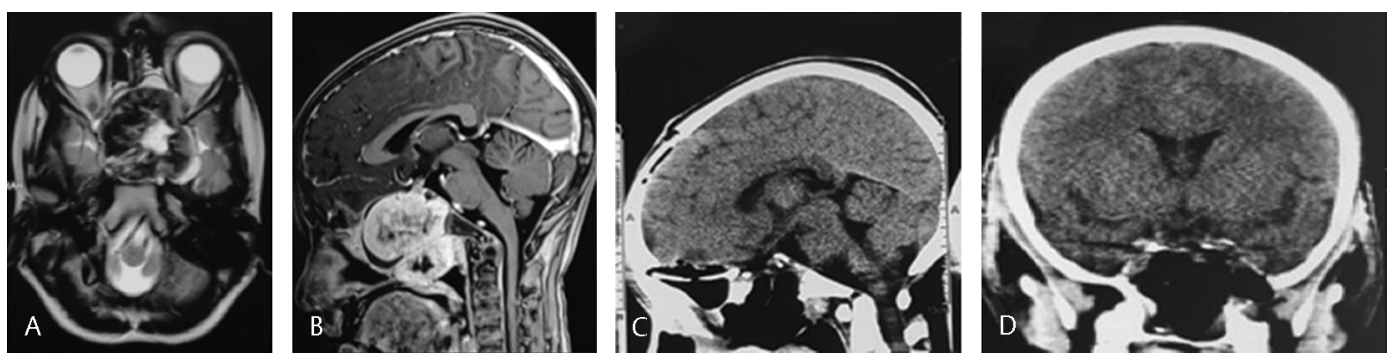

Fig. 2 (A and B) Axial and sagittal MRI showing mass in paranasal sinus and clival region. (C and $\mathbf{D})$ Postoperative sagittal and coronal CT scan showing complete excision of tumor.

\section{b. Craniotomy and osteotomy}

A burr hole was created at bilateral McCarty's point and two burr holes were placed on either side of the sagittal sinus posteriorly. A bifrontal craniotomy was raised as low as possible by connecting the above burr holes, and bone flap was raised in a single piece ( - Fig. 1 B, E). A reciprocating saw was used to make a horizontal cut just above the nasion. The frontobasal dura was detached from the orbital roof, cribriform plate of ethmoid, and planum sphenoidale.

Sphenoethmoidotomy was performed for the lesions involving paranasal sinuses and clival tumors. After detachment of frontobasal dura, the crista galli was removed with the help of a bone ronguer. Olfactory nerves were sacrificed in all cases. Ethmoid sinuses were reached by drilling the roof of ethmoid sinus with the help of high-speed drill.

\section{c. Excision and reconstruction}

Tumours having extension into paranasal sinuses, nasal cavity, and sphenoclival region were approached initially from the opening in ethmoid sinus. Gradually, piecemeal removal of tumor was started from the ethmoid sinus and then approached from maxillary and sphenoid sinus. After tumor removal from the sphenoid, the remaining part of tumor from the clival region was also removed. Meticulous hemostasis was achieved after complete excision of the tumor. Biopsy was taken and sent for histopathological examination.

The defect thus created in the anterior skull base was repaired by autologous bone graft harvested from the inner table of frontal bone. The inadvertent cuts or tears in the frontal dura were repaired primarily and further strengthened by fibrin glue to obtain water-tight dural closure at the end of the procedure ( - Fig. 1C, D).

In patients with frontonasal-orbital encephalocele, bony defects were found in the anterior frontal base, ethmoid, ocular, and nasal region. The dural sac entering into the defect was identified and cut at their entry, and contents were excised. A bone graft prepared by splitting the craniotomy bone, according to the defect at anterior skull base, was placed on the site of defect. The bone graft was then secured at that place with the help of fibrin glue. In one case, titanium mesh was placed at the medial orbital wall for reconstruction. The nose was also reconstructed with the help of titanium mesh. Dura was repaired with the help of pericranial graft.
It was first sutured with dura at all corners; subsequently, it was secured with gel foam and fibrin glue. The help of plastic surgeon was taken to reconstruct the nose by excising the redundant skin and also for nasal bridge reconstruction.

\section{Results}

Gross total excision of tumor was performed in all the four cases having skull base tumor ( $\mathbf{- F i g}$. 2). Two out of four cases showed significant improvement in visual acuity in the postoperative period. One case had only perception of light preoperatively, which improved to 6/36 and 6/24 in right and left eye postoperatively at 6 months follow-up. Histopathological examination (HPE) of both cases came out to be of nasopharyngeal angiofibroma. HPE of the rest of the two patients with skull base tumor showed clival chordoma and fungal granuloma, respectively. Patient of clival chordoma received chemotherapy and radiotherapy, whereas amphotericin B was administered in a patient of fungal granuloma, as per standard protocol.

Two of our cases developed orbitofacial edema after surgery, one case developed superficial wound infection and CSF rhinorrhea. All of these cases improved subsequently on conservative management. Loss of olfaction was observed in all the cases due to sacrifice of bilateral olfactory nerves.

Follow-up ranged between 6 months to 3 years. Both cases of nasopharyngeal angiofibroma were doing well at an average follow-up of 1 year with no residual tumor, whereas no recurrence was observed in a case of clival chordoma at 2 years of follow-up. One of our case of fungal granuloma showed recurrence at 1.5 years of follow-up and is being treated by amphotericin B again.

Two cases of frontonaso-orbital encephalocele showed acceptable cosmesis at 1 year of follow-up. One of our cases was advised surgery by the plastic surgeon for the reconstruction of nose ( $\mathbf{- F i g}$. $\mathbf{3}$ ).

\section{Discussion}

Lesions of skull base (anterior, middle, and posterior), paranasal sinuses, and clival region pose a unique surgical challenge to the skull base surgeons. These tumors may further extend into the brain or brainstem and can erode bony structures in the vicinity. The surgical approach for these types of lesions includes transfacial, transmaxillary, transphenoidal, and transoral. ${ }^{4}$ These approaches result in gross total excision 

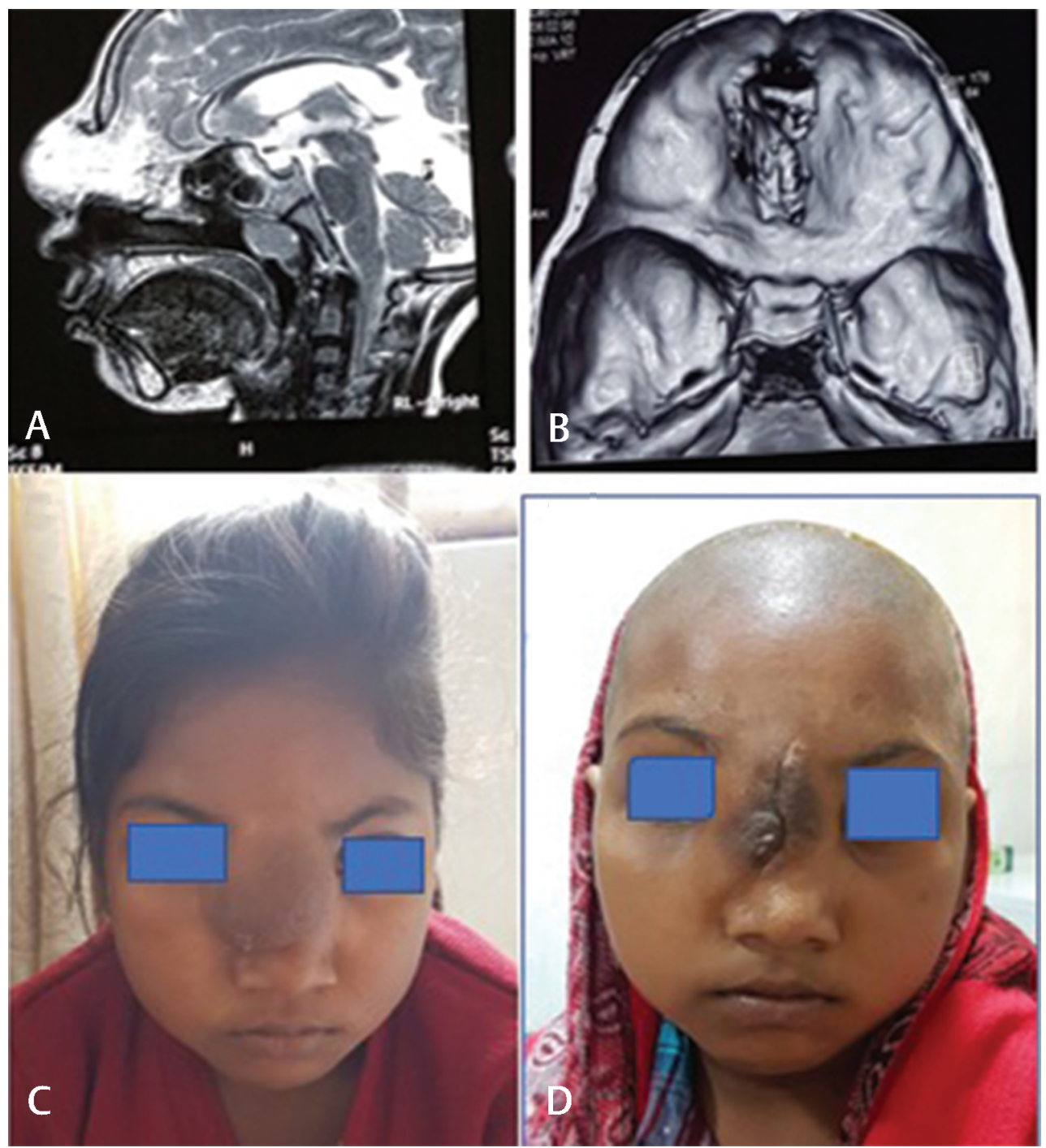

Fig. 3 (A) Sagittal MRI showing protrusion of intracranial contents into naso-orbital region. (B) 3D CT scan showing large defect at the base of anterior cranial fossa. (C) Preoperative clinical photograph of the patient. (D) Postoperative clinical photograph after surgery.

at the cost of adequate surgical exposure. To obtain better exposure, a variety of new approaches or a combination of the above-mentioned approach along with cranial approach have been developed. The combined craniofacial approach by Ray and McLean for retinoblastoma and by Smith et al for paranasal sinus tumor was developed. ${ }^{5}$

The extended frontobasal approach is indicated for the midline tumors of skull base (anterior, middle, and posterior), having extension into paranasal sinuses, sellar and parasellar region, and sphenoclival region. ${ }^{1}$ This approach can also be employed for congenital craniofacial anomalies, aneurysms, trauma, and CSF leak. ${ }^{6-8}$ In the present series, four cases having extensive skull base tumor and two cases of congenital craniofacial anomalies were operated upon by this approach.

Derome first described the transbasal approach for the removal of sphenoidoethmoidal tumors. ${ }^{2}$ Frazier in 1913 first removed the orbital rim for additional exposure of skull base. ${ }^{9}$

These additional osteotomies gained wide acceptance since then. ${ }^{10-14}$ Sekhar was the first to introduce the concept of bifrontal craniotomy along with orbitonasal osteotomy and sphenoethmoidectomy. ${ }^{1}$

In the present series, four patients underwent bifrontal craniotomy along with sphenoethmoidotomy to deal with the tumors of skull base with large extensions into paranasal sinuses, sellar region, and up to sphenoclival region. Here, we did not perform naso-orbital osteotomy, as the exposure was quite adequate after sphenoethmoidotomy, and clivus was clearly visualized. The help of microscope was taken for depth perception of tumor, and gross total excision was performed. This approach is cosmetically good and at the same time provides adequate access to the skull base.

Orbital osteotomy restricted up to the medial aspect of supraorbital foramen was performed in two cases of frontonaso-orbital encephalocele. ${ }^{15}$ The defect was then clearly defined, and reconstruction was performed. In one case, a titanium mesh was placed to reconstruct the bridge of nose and close the defect on the medial orbital wall.

Although preservation of olfaction was described by Spetzler et $\mathrm{al}^{13,16}$ it could not be preserved in a large number 
of patients. Three of our cases had loss of olfaction preoperatively, and the fourth case developed postoperative anosmia. Hence, all of our cases had postoperative anosmia because of the sacrifice of bilateral olfactory nerves. Two children with encephalocele also sacrificed of their olfactory nerves. CSF rhinorrhea is a common complication of this approach if meticulous repair is not performed. In our series of six cases, only one case had CSF rhinorrhea postoperatively, which was managed conservatively with acetazolamide and head-end elevation. He improved subsequently within 3 days. One of our cases developed superficial wound infection which was managed conservatively and improved completely on antibiotics. Significant orbitofacial edema was observed in two patients within 48 hours of surgery. It lasted for 5 days without any untoward sequalae on conservative management.

\section{Conclusion}

The extended frontobasal approach is an excellent approach for skull base lesions (both congenital and acquired). It provides adequate exposure up to the clival region. Most importantly, it obviates the more aggressive and disfiguring anterior approaches. We therefore conclude that this approach is suitable to treat a vast majority of extensive sphenoclival tumor, that is, clival chordoma and fungal granuloma, and malformative lesions with extension into adjacent structures. Cases having large defects at anterior skull base can also be repaired successfully with this approach.

\section{Funding}

None.

\section{Conflict of Interest}

None declared.

\section{References}

1 Sekhar LN, Nanda A, Sen CN, Snyderman CN, Janecka IP. The extended frontal approach to tumors of the anterior, middle, and posterior skull base. J Neurosurg 1992;76(2):198-206
2 Derome P, Akerman M, Anquez L, et al. Les tumeurs sphénoethmoïdales. Possibilités d'exérèse et de réparation chirurgicales. Neurochirurgie 1972;18, Suppl 1):161-164

3 Gupta SK, Khosla VK, Sharma BS. Bilateral frontoorbito-zygomatic craniotomy-a combined extended frontal and orbitozygomatic approach. Neurol India 2000;48(4):361-364

4 Liu JK, Decker D, Schaefer SD, et al. Zones of approach for craniofacial resection: minimizing facial incisions for resection of anterior cranial base and paranasal sinus tumors. Neurosurgery 2003;53(5):1126-1135, discussion 1135-1137

5 Smith RR, Klopp CT, Williams JM. Surgical treatment of cancer of the frontal sinus and adjacent areas. Cancer 1954; 7(5):991-994

6 Raveh J, Laedrach K, Speiser M, et al. The subcranial approach for fronto-orbital and anteroposterior skull-base tumors. Arch Otolaryngol Head Neck Surg 1993;119(4): 385-393

7 Raveh J. Neurosurgical forum comments. J Neurosurg 1992;77:656

8 Georgantopoulou A, Hodgkinson PD, Gerber CJ. Cranial-base surgery: a reconstructive algorithm. Br J Plast Surg 2003; 56(1):10-13

9 Frazier $\mathrm{CH}$. An approach to the hypophysis through anterior cranial fossa. Ann Surg 1913;57(2):145-150

10 Blacklock JB, Weber RS, Lee YY, Goepfert H. Transcranial resection of tumors of the paranasal sinuses and nasal cavity. J Neurosurg 1989;71(1):10-15

11 Jackson IT, Marsh WR, Bite U, Hide TA. Craniofacial osteotomies to facilitate skull base tumour resection. Br J Plast Surg 1986;39(2):153-160

12 Uttley D, Moore A, Archer DJ. Surgical management of midline skull-base tumors: a newapproach.JNeurosurg 1989;71(5Pt1): 705-710

13 Spetzler RF, Herman JM, Beals S, Joganic E, Milligan J. Preservation of olfaction in anterior craniofacial approaches. J Neurosurg 1993;79(1):48-52

14 Jones NF, Schramm VL, Sekhar LN. Reconstruction of the cranial base following tumour resection. Br J Plast Surg 1987;40(2): 155-162

15 Safaee MM, McDermott MW, Benet A, Theodosopoulos PV. Tailored extended bifrontal craniotomy for anterior skull base tumors: anatomic description of a modified surgical technique and case series. Oper Neurosurg (Hagerstown) 2018; 14(4):386-394

16 Honeybul S, Neil-Dwyer D, Lang DA, Evans BT. Extended transbasal approach with preservation of olfaction: ananatomical study. Br J Oral Maxillofac Surg 2001;39(2):149-157 